\title{
Toys with Wings: Creating Value through Collaborative Entrepreneurial Mindset Learning
}

\author{
Jonathan Han (Harvard University) \\ Natalia Han (RTI Health Solutions) \\ Curtis Abel (Worcester Polytechnic Institute) \\ Ahmet Can Sabuncu (Worcester Polytechnic Institute)
}

KEYWORDS: Vygotsky Cycle.

In recent years, more universities have been integrating Entrepreneurial Minded Learning (EML) into the engineering curriculum. This learning approach aims to develop an entrepreneurial mindset that drives students to discover opportunities, develop stakeholder insight, and create societal value. It helps students think beyond technical content when designing products to solve problems, and deepens their understanding of customer needs and external factors influencing customer behavior. These factors play a key role in determining how much value the product creates for the customer.

Toys with Wings is an emerging learning and teaching experience in a junior-level Mechanical Engineering course at Worcester Polytechnic Institute in Massachusetts. It aims to help students develop an entrepreneurial mindset by using the Vygotsky Cycle - a learning theory that uses social interaction to strengthen comprehension -- to complement the engineering design process. Students create milestones that match the incremental steps in the Vygotsky Cycle to show how cognition and entrepreneurial mindset grow throughout the project. Student surveys indicate that Toys with Wings was successful in stimulating student interest and understanding.

\section{Helping Underserved Populations}

Toys with Wings requires our college students to teach engineering and entrepreneurship to Afghan high school students. In this teaching exercise, students work in groups to create a STEM kit comprised of a useful tool and an instructional booklet outlining the procedures to build it. Although these kits are not actually shipped to Afghanistan, students develop entrepreneurial thinking and empathy by intentionally seeking to create an educational toy with potential societal value. In this project, we refer to these products as "toys" to emphasize that they are fun and engaging to build. For instance, one group of students created a "California Thrasher Soda Can Opener," a toy that uses a beak-like four-bar mechanism to open soda cans for individuals with disabilities. Many of you probably have heard that teaching is the best way to learn. The project confirms our hypothesis that teaching to underserved populations is also a good learning opportunity for our college students.

Afghanistan is a country with significant needs. Only $78 \%$ of school-aged children go to school in Afghanistan [1], and the 5\% enrollment into higher education is even more dire ${ }^{[2]}$. Children who attend school do not get highquality education in Afghanistan, mainly because teachers are not sufficiently trained and schools have few resources for laboratory-based education [3]. High schools lack the resources to enable their students to tinker and to create designs.

Can we make a positive change for Afghan school-aged children in their access and view to science and technology? Our project aims to answer this question.

\section{PROJECT DESCRIPTION}

Toys with Wings is conducted in a junior-level Mechanical Engineering course on Kinematics of Mechanisms at WPI. Very briefly, students in this course create mechanisms and analyze their motion using vector algebra. Course exercises utilize advanced mathematics as students use complex numbers as vectors to represent mechanisms. However, these learning exercises do not usually include teaching entrepreneurial thinking. We have two major goals in this project: to help them better understand mechanisms and to learn to think like entrepreneurs in seeing opportunities. 
After considering all the learning models, we decided to use the "Vygotsky Cycle" to scaffold the learning activities in our project. Lev Vygotsky hypothesized that cognitive development -- which encompasses perception, learning, and reasoning -- is developed through social interactions. Accordingly, students learn by working together to construct new knowledge and understanding, rather than being delivered information from the teacher. For instance, to design a walker for an elderly person, students will benefit from brainstorming ideas with peers and understanding stakeholder pain points to gain insight into the problem, rather than relying just on theory and their own perceptions to develop the solution. Therefore, this led us to think that the Vygotsky Cycle is the optimum tool as design inputs and verification in this project depends on social interactions (i.e. understanding the customers' needs through empathy) ${ }^{[4]}$.

The Vygotsky Cycle expresses the learning process as a function of display and realization, which are independent learning elements. Accordingly, understanding develops in five sequential steps (Figure 1): (1) appropriation- students internalize the knowledge, (2) transformation- students produce their own understanding, (3) publication- students publicly expresses their conceptions, (4) conventionalizationstudents' knowledge is fully integrated into social domain, and the final step, (5) students become teachers if desired. We summarized these steps in Figure 1. Our motivation is that if students can cycle through the steps in Figure 1, they will be able to acquire a solid understanding of the technical content. We refer to the work by Cheville and Thompson for further details on the Vygotsky cycle ${ }^{[5] .}$

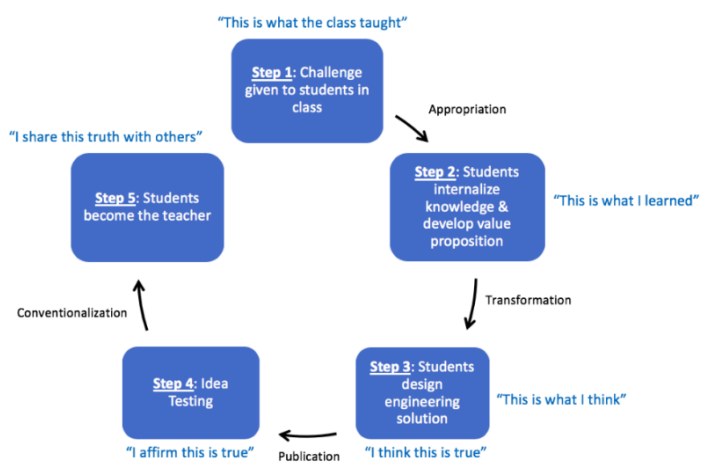

Figure 1. Toys with Wings Vygotsky Cycle. Depiction of the sequential steps of Vygotsky's social-constructivist learning model in relation to the current project, Toys with Wings ${ }^{[5]}$.

We also follow a framework devised by the Kern Entrepreneurial Engineering Network (KEEN) to embed EML into the Toys with Wings project ${ }^{[6]}$. This framework basically embeds EML within Project-Based Learning (PBL) by adapting technical engineering instruction to promote and encourage curiosity of our changing world and discovery of opportunities to create societal value. While there are many definitions, qualities, and metacognitive attributes of entrepreneurial mindset as summarized in the scholarly literature ${ }^{[7]}$, the perspectives are essentially saying similar things, but with a different focus. The KEEN framework is used here because it integrates nicely with the Vygotsky cycle, engineering design, and the class learning activity.

We place students in a hypothetical scenario that stimulates interest in the project. Students are placed in the position of the owner of a hypothetical company called Let's Play. Let's Play is a startup specializing in making educational toys for various age groups and is working on a proposal that is in response to a solicitation by World Bank. Because Afghanistan lacks resources to provide STEM education, World Bank is asking entrepreneurs to build educational engineering kits for Afghanistan. In this hypothetical scenario, the designs should be relevant to daily life or industry in Afghanistan to increase the value of the product from a marketing perspective, per instruction by World Bank. College students are tasked to work in groups to develop an educational toy that addresses a social need in Afghanistan. Our students progress from step 1 until step 5 in the Vygotsky cycle. The learning activities and student deliverables, which are designed considering the Vygotsky cycle, are summarized in Figure 2.

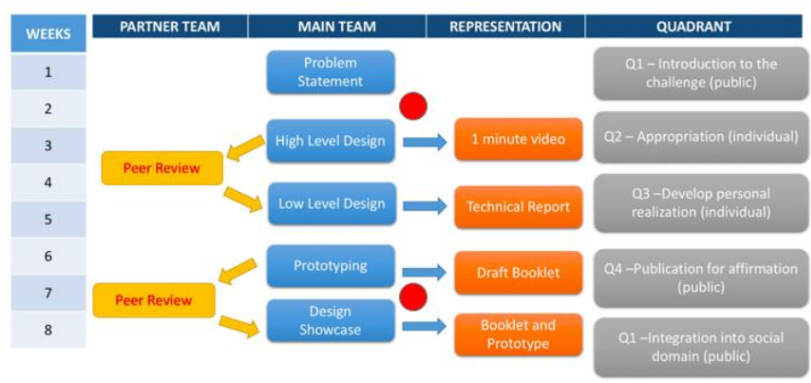

Figure 2. Toys with Wings timeline. A summary of the deliverables and timeline of the project. Students start 
with a problem statement and create representations for each step of the Vygotsky Cycle, receiving faculty and peer feedback throughout the developmental process. The red dots in the figure indicate possible engagement time points with outside stakeholders.

In the final week of the course, students produce an instructional booklet that teaches their design to Afghan students. This takes them to the last step in the Vygotsky cycle. This booklet teaches Afghan students how to build the toy and the engineering principles behind it. The booklet is designed so that it can be easily understood by someone with no engineering background. We show an exemplary cover page from one team's work in Figure 3.

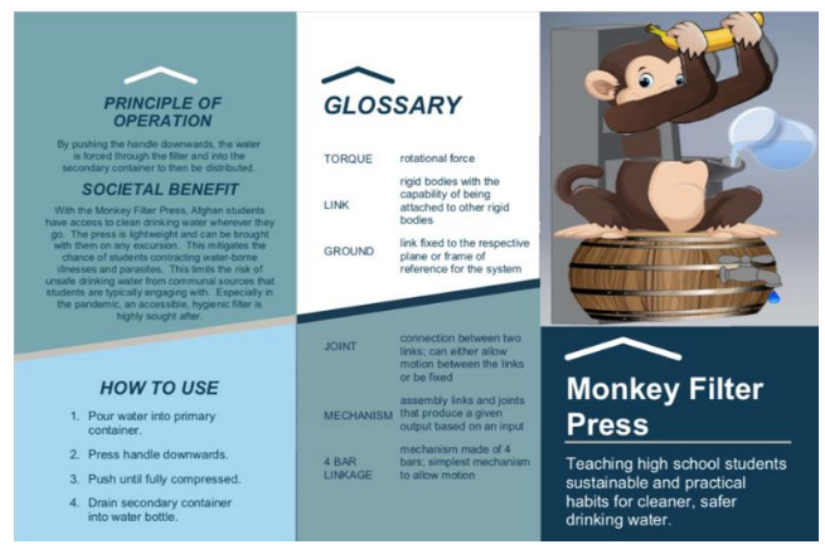

Figure 3. Example of student work. A page from a team's instructional booklet. This group decided to create a water filter in order to reduce the chance of Afghan students contracting parasites and water-borne illnesses, which are common in Afghanistan.

In Toys with Wings, students become more curious as they explore many different types of problems in the Afghan cultural context. While the students were not able to interview stakeholders from Afghanistan, they were encouraged to do secondary research on the lifestyle in Afghanistan and watch videos to help sensitize them to the challenges and needs of the people. These activities help develop empathy. According to a survey we conducted in our last offering of this course, almost all student teams used surveys, articles and reports that are available online. Some student teams relied on a book that they read about Afghanistan. Ideally, students can interview an international student or a community member who was born in Afghanistan.
Developing a value proposition encourages students to think about not just the immediate needs of the user, but also how it benefits other stakeholders. In this way, it encourages students to approach a problem as an opportunity to help many others, rather than to solve a single problem. For instance, one group of students decided to design an active pressure water filter kit (Figure 3) that not only teaches Afghan students about mechanical advantage and quick-return mechanisms, but also potentially helps the general population in Afghanistan access clean, filtered water. By utilizing a systems-thinking approach to make connections between their technical skills, knowledge regarding mechanisms, and information about the various stakeholders, students were able to see multiple viewpoints and think more broadly than just about mechanisms when designing a product for Afghan high school students. Students in this team approached this project as an opportunity to address Afghanistan's clean water shortage, allowing them to engineer a solution that impacts individuals, groups, and society as a whole.

\section{RESULTS AND DISCUSSION}

Students were given a survey to complete after the project wrapped up. The results of the survey revealed positive learning outcomes of Toys with Wings. First, the consumer-based approach of the project nurtured students' curiosity and helped them develop an eye for impact. Through intensive research, student groups sought out new ways to create meaningful value for people in Afghanistan.

Here is a response from one student:

We tried to make connections with our project customers by learning about the current educational system in Afghanistan and understanding how it works. We learned that education in Afghanistan typically emphasizes dictation, memorization, and recitation. However, organizations are trying to train teachers with new interactive teaching methods that encourage critical thinking, problem solving, and interpreting and evaluating information. Our project fits right into that new teaching philosophy. We researched needs in different Afghan industries by doing Google searches online. During one of these searches we discovered that pine nut harvesting was a lucrative industry in Afghanistan, however it was very time consuming. This is how we came up with the idea of trying to make a product that simplifies one step in the pine nut harvesting process. 
It was clear from the responses that students benefitted from a specific target audience. They were able to implement the important design practice of understanding the audience in order to identify unprecedented opportunities of impact. Second, the opportunity to create real value motivated and engaged students even more. In Toys with Wings, students created a product not only to achieve a grade, but also to create a lasting impact on Afghan students.

The opportunity to assist and educate underprivileged students in a foreign country provided a motivation unlike the large majority of past engineering projects. The prompt let them apply an advanced level of creativity to a real-world purpose, and it was equally challenging and rewarding for the students.

Lastly, the responses also suggested that teaching others through an instructional booklet helped stimulate their own understanding of engineering concepts. Having to create an IKEA-like manual required them to keep track of their iterations and organize their progress/thoughts throughout the ideation process.

\section{Key Takeaways}

Overall, we noticed that students found "success and personal fulfillment coupling their skills with a mindset to create extraordinary value for others ${ }^{[8]}$." Here are some key takeaways we have compiled from conducting this project:

- Students excel when given a purpose to their creations. Engaging students in meaningful projects leads to greater motivation.

- The Vygotsky cycle helped students develop their initial value proposition, design verification, and dissemination in a sequential and a logical manner.

- It is important to include a specific target audience through which students can identify opportunities to create impact. The process of conducting research also helps students grow curiosity and make meaningful discoveries.

- Teaching others is an important step to content mastery. Other studies have shown that learning with the intention of teaching leads to better understanding and performance when tested upon ${ }^{[9]}$. With a teacher's mentality, students employ useful learning strategies such as identifying main points and organizing information into a concise summary ${ }^{[9]}$.
Going forward, we hope to connect our students with stakeholders in Afghanistan to help students develop better customer insights and pain points. This stage of empathizing will help students create products that are of superior value to the Afghan society.

\section{REFERENCES}

[1] Akseer, Tabasum, and Fahim Ahmad Yousufzai . "Afghanistan in 2019 A Survey of the Afghan People." The Asia Foundation, 2019, asiafoundation.org/wherewe- work/afghanistan/survey/.

[2] Roof, D. J. (2015). Day-By-Day: Higher Education in Afghanistan. FIRE: Forum for International Research in Education, 1(3). Retrieved from http://preserve.lehigh.edu/fire/vol1/iss3/6

[3] Kazemi, Mohammad Mustafa. "School Science Labs for Rural Afghanistan." The Asia Foundation, 10 Oct. 2018, asiafoundation.org/2018/10/10/school-sciencelabs-for-rural- afghanistan/.

[4] "Overview of Learning Theories." GSI Teaching Resource Center, gsi.berkeley.edu/gsi-guidecontents/learning-theory-research/learning-overview/.

[5] Cheville, R. A., \& Thompson, M. S. (2018). ASEE Annual Conference \& Exposition, Salt Lake City, UT.

[6] KEEN, "Educational Outcomes," KEEN , [Online].

[7] Naumann, Christiane (2017). Entrepreneurial Mindset: A Synthetic Literature Review. Entrepreneurial Business and Economics Review, Volume 5, No. 3, 149-172.

[8] "The 3C's of Entrepreneurial Mindset," KEEN, [Online]. Available:https://engineeringunleashed.com $/ \mathrm{m}$ indset-matters.aspx.

[9] Nestojko, J., Bui, D., Kornell, N., \& Bjork, E. (2014). Expecting to teach enhances learning and organization of knowledge in free recall of text passages. Memory \& Cognition, 42(7), 1038- 1048 https://doi.org/10.3758/s13421-014-0416-z. 